\title{
Eı Nino Döneminde Yaşanan Ekstrem Hava Olaylarının Bulaşıcı Hastalıklar Üzerindeki Etkileri
}

\author{
Effects of Extreme Weather Events on Infectious Diseases Which Experienced \\ During El Niño
}

\author{
Mehmet AKALIN \\ Sosyal Güvenlik Kurumu Sigorta Primleri Genel Müdürlü̆̈̈̈, Ankara
}

\begin{abstract}
Özet: El Nino döneminde Dünyanın bazı bölgelerinde ekstrem yağışlar ve seller meydana gelirken, bazı bölgelerinde ise uzun süren kuraklıkların yaşandığı görülmektedir. Bu çalışmada El Nino döneminde yaşanan kasırga, tayfun, seller ve uzun süren kuraklıklar gibi ekstrem hava olaylarının bulaşıcı hastalıkları hangi yönde etkilediği konu edilmiştir. Bunun için patojen ve vektörler ile insan davranışlarının bulaşıcı hastalıkların yayılmasındaki önemi incelenmiştir.

Anahtar sözcükler: El Nino, LA Nina, tayfun, sel, kasırga, kuraklık, ekstrem iklim olayları, bulaşıcı hastalıklar.
\end{abstract}

\begin{abstract}
During El Nino, in some areas of world excessive rains and floods takes place and has encountered long-lasting drought. In this study, the effects of infectious diseases which extreme whether events such as; hurricanes, typhoons, floods and prolonged droughts which is occurs after El Nino, are mentioned. Thus for it is investigated in this study importance of spreading infectious diseases between pathogens, vectors and human behaviour.
\end{abstract}

Key words: El Nino, typhoons, hurricanes, floods, drought, extreme whether events, infectious diseases.

\section{Giriş}

Tarihte seller, kuraklıklar ve kıtlıklar gibi salgın hastalıklara ve kitlesel ölümlere sebep olmuş birçok büyük felaket yaşanmıştır. Bu karmaşık ve büyük çaplı felaketlerden yoksul toplumlar en büyük darbeyi almış olsalar da günümüzün endüstrileşmiş zengin toplumlarının da iklim değişikliğinin sebep olduğu felaketlerin yıkıcı etkilerini hasarsız şekilde atlatması söz konusu olamamıştır.

Küresel ısınma ve iklim değişikliğinin sebep olduğu ekstrem iklim olaylarının yaşanma sıklığı son zamanlarda artış göstermektedir. Yıkıcı etkileri şiddetlenerek artan bu iklim olaylarını ise iki kategoride incelemek mümkündür. Bunlardan birincisi, basit iklim verilerine dayanan basit ekstrem hava olaylarıdır. Basit iklim ekstremleri, çok yüksek ve çok düşük 1sı değerlerinin sonucunda yaşanan hava koşullarının sebep olduğu olaylarıdır. Ekstrem iklim olaylarının bir diğeri ise, daha karmaşık şekillerde gelişen ve her yıl istikrarlı bir şekilde herhangi bir yerde görülmeyen kuraklık, tayfun, siklon, kasırga ve sel gibi karmaşık ekstrem hava olaylarıdır(WHO, 2003).

Yükselen küresel sıcaklık değerlerinin sebep olduğu sıcaklık ekstremlerinin sera gazı emisyonlarının azaltılmadığı sürece daha da artarak devam etmesi beklenmektedir. Bu bakımdan yaşadığımız yüzyılın sonuna kadar ortalama küresel sıcaklık değerlerinde $1.80 \mathrm{C}-40 \mathrm{C}$ arasında bir artış yaşanması öngörülmektedir(IPCC, 2007). Bu da gelecekte daha sik bir şekilde sıcak hava dalgalarının, ekstrem sıcaklıklarının ve ekstrem hava olaylarının yaşanacağının bir göstergesidir.

\section{EI Nino ve Karmaşık Ekstrem Hava Olayları}

Pasifik Okyanusu'nun ekstrem ısınması nedeniyle iklimlerin ani olarak değişmesi anlamına gelen El Niño Güney Salınımı (El Niño South Oscillation); okyanus akıntılarının Doğu Pasifik'e doğru 1lık su akımı oluşturmasıyla meydana gelmektedir. El NiNO Güney Amerika Kıtasında Peru ve 
Ekvador kıyılarındaki okyanus yüzey sularının 1sınmasına sebep olmaktadır. Güneş enerjisi ve okyanus akıntı sistemlerinin etkisiyle oluşan yüzey sularındaki bu 1sınmanın kesin olmamakla birlikte genellikle 2-7 y1llık aralıklarla oluştuğu görülmektedir. Bu anormal durum boyunca Dünya genelinde atmosfer, sıcaklıklar, rüzgârlar, nem miktarı, ve okyanus akıntıları gibi iklim elemanlarında fiziksel değişimler meydana gelmektedir. Bu fiziksel değişimler hem iklimsel hem biyolojik olarak etkisini göstermektedir.

İklimsel etki bakımından El NINO döneminde atmosfer basıncının artması veya azalması nedeniyle siklonlar ve tayfunlar meydana gelebilmektedir. Ayrıca bazı bölgelerde ekstrem yağışlar bazı bölgelerde ise uzun süren kuraklıklar yaşanabilmektedir. El NINO dönemlerindeki iklimsel değişimler özellikle Amerika Kıtası'nda ve Pasifik Okyanusu'nda etkili olmaktadır. El NiNO bu bölgelerin doğu enlemlerinde genellikle kuraklık olarak kendini gösterirken, batı enlemlerinde ise şiddetli yağış ve taşkınlara sebep olmaktadır.

\section{El Nino- Bulaşıcı Hastalık İlişkisi}

Ekstremiklim olayları çoğunlukla zorunlu göçlere ve salgın hastalıklara sebep olduğundan El Nino döneminde yaşanan ekstremiklim olayları ile iklim göçleri ve salgın hastalık ilişkisinin iyi anlaşılması gerekmektedir. Sosyal mekanizmalar El Nino döneminde yaşanan ekstremiklim olaylarının etkilerini göstermek açısından önemlidir. Ancak etki düzeyinin belirlenmesi daha karmaşık süreçleri içerdiğinden sosyal mekanizmalar ekstremiklim olaylarının etki düzeylerinin belirlenmesinde zaman zaman yetersiz kalabilmektedir. Nitekim, insanları gruplar halinde göçe zorlayan, iklim değişikliğinin sebep olduğu ekstrem iklim olaylarının yanında başka sebepler de olabilmektedir. İç savaşlar, siyasi bunalımlar, daha iyi bir yaşam kurma umudu bu sebeplerden bazılarıdır(WHO, 2003). Ancak iklim mültecilerinin yaşamak zorunda oldukları kamplardaki sağlıksız yaşam koşuları, altyapı yetersizlikleri, kirli ve hastalıklı sular El Nino döneminle ekstremiklim olayları ve hastalıklar arasındaki ilişkileri anlamlandırabilmektedir.

Diğer taraftan fiziksel mekanizmalar ekstremiklim olaylarının insan sağlığına etkilerini daha kolay açıklayabilmektedir. Örneğin, ekstremyağışların sebep olduğu seller sonucu, sel sularının insan ve hayvan atıklarıyla temas edip insanların kullanım ve içme sularına karışması, kolera, tifo ve ishal gibi hastalıklarda artışların görülmesine sebep olabilmektedir. Ayrıca, kuraklık nedeniyle azalan su kaynakları, su ve gıda kirlenmesine neden olacağından bu yolla bulaşacak hastalıkların yaygınlaşması da kaçınılmaz olabilmektedir.

Ekosistemler açısından bakıldığında ise, iklim ve insan toplulukları arasında bulaşıcı hastalıklar bakımından interaktif bir ilişki olduğu görülebilir. Örneğin, bulaşıcı hastalıkların sebepleri geçen yıllarda hep ekstremnüfuslanma, çarpık kentleşme, yetersiz altyapılar, arazi kullanımındaki değişmeler ve değişen tarım pratikleri, uluslararası geziler sonucu taşınan virüsler ve halk sağlığı hizmetlerinin yetersizliğinde aranmıştır(IPCC, 2001). Günümüzde ise doğal ekosistemlerin tahribatı sonucu değişen yaşam döngüsünün bulaşıcı hastalıklarda artışa sebep olduğu kabul görmüştür.

\section{EI Nino Döneminde Yaşanan EkstremHava Olayları ve Bulaşıcı Hastalıklar}

Yağışlarla hastalık yayan vektörler arasında anlamlı ilişkiler bulunmaktadır. Bunun bir nedeni yağışlar sonrası oluşan durgun sularda vektörlerin kolaylıkla çoğalıp gelişebilmeleridir. Nitekim ekstremiklim olayları sonucu meydana gelen ekstrem yağışların görüldüğü bölgelerde bulaşıcı hastalık yayan bazı sivrisinekler için yaşama ve üreme yerleri de oluşmuş olmaktadır. Aynı zamanda kuraklık sonucu kuruyan nehir yataklarında da sivrisineklerin beslenmesi ve çoğalması için uygun ortamlar oluşabilmektedir. Diğer taraftan, ekstremyağışlar hastalık yayan vektörlerin beslenme ve üreme bölgelerini yıkayarak başta sivrisinekler olmak üzere bazı vektörtlere yaşama imkânı vermeyebilmektedir. Bu da bölgede daha önce hüküm süren vektör kaynaklı hastalıkların azalmasına sebep olabilmektedir. 
Ekstrem yağışlar sonucu oluşan vektör kaynaklı hastalıkların yayılmasında, sıcaklık değerlerindeki değişimler de önemli bir rol oynamaktadır. Nitekim artan sıcaklıklar vektör popülasyonunun çoğalma süresinin kısalmasına yol açmaktadır. Ayrıca artan sıcaklık değerleri, mikropların gelişim sürelerini azaltmakta ve vektörlerin hastalıkları daha çabuk yaymalarına sebep olmaktadır(WHO, 2003). Yağışların zamanı ve diğer iklimsel özellikler ise hastalık taşıyan vektörlerin yaşamalarına ve çoğalmalarına etki eden diğer faktörleri oluşturmaktadır(WHO, 2003).

El nino döneminde yaşanan ekstrem yağışlar nedeniyle yayılma imkanı bulan bazı sivrisinek türleri, etkili oldukları bu bölgelerde sıtma, dang humması, lyme ve sarı ateş gibi vektör kaynaklı hastalıklara sebep olurken, kirlenen sularda popülasyonu artan bazı kemirgen türleri de hantavirüs, lestospiroz ve veba gibi bulaşıcı hastalıkların yayılmasına aracılık edebilmektedir.

Tablo 1. Ortalamanın Üzerindeki Yağışların İnsan Sağlığını Etkileme Mekanizmaları

\begin{tabular}{|c|c|c|c|c|c|}
\hline EKSTREM İKLİM OLAYI & $\begin{array}{l}\text { EKSTREM } \\
\text { OLAYININ } \\
\text { TÜRÜ }\end{array}$ & $\begin{array}{r}\text { İKLİM } \\
\text { ETKİ }\end{array}$ & $\begin{array}{l}\text { EKSTREM } \\
\text { OLAYININ } \\
\text { DERECESİ }\end{array}$ & $\overline{\text { İKLİM }}$ & $\begin{array}{l}\text { SAĞLIĞAPOTANSİYEL } \\
\text { ETKİLERİ }\end{array}$ \\
\hline Ekstrem yağışlar & Meteorolojik & & Ekstrem iklim o & olay1 & $\begin{array}{l}\text { Sivrisinek popülasyonundaki artış } \\
\text { Üreme alanlarının yok olması } \\
\text { nedeniyle sivrisinek } \\
\text { popülasyonundaki azalış }\end{array}$ \\
\hline Seller & Hidrolojik & & $\begin{array}{l}\text { Nehir ve } \quad b \\
\text { taşması ve } \\
\text { zarar görmesi }\end{array}$ & $\begin{array}{c}\text { barajlarin } \\
\text { ekinlerin }\end{array}$ & $\begin{array}{l}\text { Yüzey sularının } \quad \begin{array}{r}\text { kirlenmesi } \\
\text { sivrisinek }\end{array} \\
\text { popülasyonunda artış } \\
\text { Suların dışkı ya da idrarla teması } \\
\text { nedeniyle } \\
\text { sivrisinekpopülasyonunda artış }\end{array}$ \\
\hline Seller & Sosyal & & $\begin{array}{l}\text { Nehir ve } \quad b \\
\text { taşması ve } \\
\text { zarar görmesi }\end{array}$ & $\begin{array}{r}\text { barajların } \\
\text { ekinlerin }\end{array}$ & $\begin{array}{l}\text { Dişkı ve idrarla temas eden sularda } \\
\text { üreme imkanı bulan } \\
\text { sivrisineklerinpopülasyonundaki } \\
\text { artış }\end{array}$ \\
\hline Seller & Y1kıcı etki & & $\begin{array}{l}\text { 10'dan fazla } \\
\text { ölmesi }\end{array}$ & kişininin & $\begin{array}{l}\text { Solunum yolu hastalıklarında ve } \\
\text { ishal vakaları sebebiyle ölümlerde } \\
\text { artış }\end{array}$ \\
\hline Seller & Felaket & & $\begin{array}{l}\text { 200'den fazla } \\
\text { etkilenmesi } \\
\text { Dış yardıma } \\
\text { duyulması }\end{array}$ & kişinin & $\begin{array}{l}\text { Solunum yolu hastalıklarında ve } \\
\text { ishal vakaları sebebiyle } \\
\text { yaralanmalarda artış }\end{array}$ \\
\hline
\end{tabular}

Kaynak: (Kovats, 1999). 
Tablo 2. Ortalamanın Altındaki Yağışların İnsan Sağlığını Etkileme Mekanizmaları

\begin{tabular}{|c|c|c|c|}
\hline EKSTREM İKLİM OLAYI & $\begin{array}{l}\text { EKSTREM } \dot{\text { IKKLIMM }} \\
\text { OLAYININ ETKİ TÜRÜ }\end{array}$ & $\begin{array}{l}\text { EKSTREM İKLİM } \\
\text { OLAYININ DERECESİ }\end{array}$ & $\begin{array}{l}\text { SAĞLIĞA } \\
\text { ETKİLERİ }\end{array}$ \\
\hline Kuraklik & Meteorolojik & $\begin{array}{l}\text { Ekstrem buharlaşma ve } \\
\text { toprak neminin azalması }\end{array}$ & $\begin{array}{lr}\text { Vektör } & \text { miktarındaki } \\
\text { değişim(kuruyan } & \text { nehir } \\
\text { yatağından beslenen } & \text { vektör } \\
\text { miktarındaki artış gibi) } & \end{array}$ \\
\hline Kuraklık & $\begin{array}{l}\text { Tarımsal/ } \\
\text { Sosyal }\end{array}$ & $\begin{array}{l}\text { Tarımsal ürün } \\
\text { miktarındaki azalma } \\
\text { Tarımdan elde edilen } \\
\text { gelirin azalması } \\
\text { Kullanılan suyun miktar } \\
\text { ve kalitesindeki düşüş }\end{array}$ & $\begin{array}{l}\text { Kitlık/Açlık/Hastalık/Kötü } \\
\text { beslenme }\end{array}$ \\
\hline Kuraklık & $\begin{array}{l}\text { Açlık/kitlık/Kuraklık } \\
\text { Felaketi }\end{array}$ & $\begin{array}{ll}\text { 10'dan fazla } & \text { kişinin } \\
\text { ölmesi } & \\
200 \text { 'den fazla } & \text { kişinin } \\
\text { etkilenmesi } \\
\begin{array}{l}\text { Dış yardıma } \\
\text { duyulması }\end{array}\end{array}$ & $\begin{array}{l}\text { Hijyen kaynaklı bulaşıcı hastalık } \\
\text { ve ölümler } \\
\text { Açlıktan ve kötü beslenmenin } \\
\text { sebep olduğu hastalıklar ve } \\
\text { ölümler } \\
\text { Göçler sebebiyle oluşan hastalık } \\
\text { ve ölümler }\end{array}$ \\
\hline
\end{tabular}

Kaynak: (Kovats, 1999).

\subsection{Sitma}

Sitma Dünya nüfusunun büyük bölümünü sarsan bulaşıcı hastalıkların başında gelmektedir. 2.5 milyar insan bu hastalıktan etkilenmekte ve her yıl ortalama 1 milyon kişi sıtma nedeniyle hayatını kaybetmektedir(WHO, 1998; WHO,2007). Sitmaya 4 farklı parazit türü sebep olmakla birlikte insanlara bu hastalık lekeli sıtma sivrisineği (anopheles mosquitoes) vasitasıyla bulaşmaktadır.

Sitmayla mücadele konusunda hükümetlerin politikalarında meydana gelen gerilemeler, 1970'li ve 1980 'li yıllarda sıtmayla mücadele araştırmalarına ayrılan fonların azalmasına sebep olarak hastalığın büyük kitleleri etkilemesine sebep olmuştur. Ayrıca, ilaç tedariki ve ilaçlama faaliyetlerine duyulan güven, ekstrem nüfuslanma ve bölgeler arası nüfus hareketleri, arazi kullanımının değişmesi ve sağlık altyapılarının yetersizliği sıtmanın günümüzde yeniden ortaya çıkıp, artmasına sebep olan diğer faktörleri oluşturmaktadır(Lindsay, ve Birley, 1996).

Sıtma; sıcaklıklar, nem oranındaki değişiklikler ve insanların bağışıklık düzeyine bağlı olarak insanları etkilemektedir(Lindsay, ve Birley, 1996). Bu faktörlerden sicaklıkların artma eğilimine girmesi yetişkin sivrisinek popülasyonunu çoğaltmakta ve daha çok parazit taşımalarına sebep olmaktadır. Ancak çok yükssek sıcaklıklar sivrisinek ve parazitler için ölümcül olabileceğinden yüksek sıcaklıkların görüldüğü bir bölgedeki sıcaklık değerlerinin biraz daha artması bölgedeki parazit ve sivrisinek popülasyonunun azalmasına sebep olabilmektedir. Diğer taraftan, soğuk bölgelerdeki küçük sıcaklık artışları bölgedeki parazit ve sivrisinek popülasyonunu arttırarak sıtma riskinin bu bölgelerde yayılmasına yol açabilmektedir(Bradley, 1993).

Mikro ve makro düzeydeki çevresel düzenlemeler de sıtmanın yayılma alanlarını etkileyebilmektedir. Örneğin, ormanların yok edilmesi bölgesel sıcaklıklarda artışa sebep olacağından hastalık yayan vektörlerde artışa sebep olabilmektedir(Hamilton, 1989).Nitekim, Afrika'daki ormansızlaşma, bitki türlerinin yok olması ve sulama olanaklarının yaygınlaşması sıtma vektörlerinin gelişip çoğalması için uygun 1 şık gören gölcüklerin oluşmasına ve hastalığın artmasına sebep olmaktadır(Chandler ve Highton, 1975).Ayrıca, ev şekillerindeki değişiklikler evin içerisindeki sıcaklık değerlerinin değişmesine ve vektörlerin ev içerisinde daha uzun süre barınmalarına ortam hazırlayabilmektedir(Garnham, 1945). 
Kuraklık ile sıtmadan kaynaklanan ölümler arasında anlamlı ilişkiler söz konusudur. Kuraklık nedeniyle meydana gelen kötü beslenme şartları insanların bağışıklık sistemini zayıflatarak bulaşıcı hastalıklara karşı insanları korunmasız hale getirebilmektedir. Bağışıklık sistemi bozulan insanlar için ileriki yıllarda hastalık riski ve hastalığı diğer insanlara bulaştırma olasılığı da artış gösterebilmektedir(WHO, 2003).

Kuraklık dönemlerinde ekosistemlerdeki değişim nedeniyle doğal avcı popülasyonu vektör popülasyonunun altında kalabilmektedir. Av-avcı arasındaki zincir halkalarının yok olması vektörlerin avcı türlerden çok daha hızlı bir şekilde çoğalmasına ve sıtma riskini daha geniş alanlara yaymalarına neden olmaktadır(Diaz ve Jones, 2000).

Yüksek bölgelerde sıtma vakalarıyla karşılaşılması bu hastalıkla iklim değişikliği ve küresel ısınma arasındaki ilişkiyi anlamlandırmaktadır. Nitekim 20 yy'ın ilk dönemlerinde sıtma vakaları Afrika, Güney Amerika ve Yeni Gine'de 1500-2500 metre yükseklikte görülmekteydi. Afrika'daki yüksek alanlarda görülen bu sitma vakaları 1950'lerde etkin medikal destek ve tedavi yöntemleriyle kontrol altına alınmış görünüyordu. Ancak El Nino' nun sebep olduğu yüksek bölgelerdeki ekstrem yağışlar ve sıcaklıklardaki artışlar bu bölgelerde sıtma vakalarının sayısında da artışların yaşanmasına sebep olmuştur.

El Nino döneminde kuraklık yaşanan bölgelerde ve yüksek bölgelerin yăğş̧ alan yamaçlarında sıtmanın yayılması için elverişli şartlar oluşabilmektedir. El Nino'nun etkili olduğu azgelişmiş ve gelişmekte olan ülkelerde yaşayan halk, altyapı yetersizliği ve felaketten korunma yöntemlerinin geliştirilmemiş olması nedeniyle sıtma tehlikesiyle daha çok karşı karşıya kalabilmektedir(WHO, 2003). Dolayısıyla Güney Amerika'nın Kuzey ülkelerinde birçok hastalık El Nino olaylarını takip eden yılda gerçekleşmektedir. 1982 yılında şiddetli El Nino olayından sonra Ekvador, Peru ve Bolivya'da sıtma vakalarının yaşanması, aynı yılda Venezüella ve Kolombiya'daki sıtma vakalarındaki artışların yaşanması bu görüşü desteklemektedir. Bu bakımdan Guyana, Kolombiya, Peru ve Venezuella'da El Nino ile sıtma vakaları arasında istatistiksel olarak anlamlı ilişkilerin olduğu söylenebilir(Gagnon, 2002).

Afrika'da ise geçtiğimiz yıllarda Sahra çölü (Sudan) ve Kalahari çölü (Nambia, Botsvana) çevresinde kuraklığın sebep olduğu sıtma vakaları yaşanmıştır. Kenya'da iki yıl süren kuraklığın ardından 1997/1998 yıllarında gerçekleşen El Nino, ekstrem yağışlara ve taşkınlara sebep olmuş, 1998 yılının Ocak ayından Mayıs ayına kadar yaşanan büyük kıtlığın da etkisiyle sıtma vakalarında büyük artışlar görülmüştür(Brown, 1998). Bu da El Nino ile sitma vakaları arasındaki anlamlı ilişkileri gösteren bir diğer örnektir.

\subsection{Dang (Dengue) Ateşi}

Dang ateşli hastalığı; vektörler aracı̆̆ıyla bulaşan en önemli hastalıklardan bir diğeridir. Genellikle tropikal ve subtropikal bölgelerde görülmektedir. Yağışlar sonrası kendiliğinden oluşan veya su depolamak amaciyla kurulan yapay göletlerde yaşama ve üreme imkânı bulanvektörler bu bölgelerde önemli ölçüde sağlık sorunlarına sebep olabilmektedir(Gubler, 1997).

Dang virüsü genellikle, vektör ve hastalık takip sisteminin etkisizliği, halk sağlığı altyapısının yetersizliği, aşırı nüfuslanma, kontrolsüz ve plansız şehirleşme gibi nedenlerle artmaktadır(Gubler, 1997). Dang virüsü "sarı humma sivrisineği”" olarak da bilinen "aedes aegypti" (ince, uzun vücutlu ve dar kanatlı bir sinek) tarafindan insan ve hayvanların sokulması yoluyla bulaşma ve yayılma imkânı bulmaktadır. Bu sineklerin bir başka türü de "aedes albapictus" dur. Bu tür ise daha soğuk ortamlarda hastalık bulaştırıp hastalığın yayılma alanının genişlemesine sebep olmaktadır.

Bazı zaman serileri analizleri sonucu elde edilen verilere göre yapılan çalışmalarda dang virüsü ile iklim özellikleri arasında ilişki kurulmuştur. Ancak bu ilişkinin doğruluğu kesin olarak kanıtlanamamıştır. Ekstrem yağışlar ve yüksek sıcaklıklar hastalığın bulaşmasını kolaylaştırmakla 


\section{Mehmet Akalın}

birlikte, yapılan bu çalışmalardan elde edilen sonuçlara göre hastalığın yayılmasında daha karmaşık çevresel faktörlerinin önemli rol oynadığ gözden kaçırılmamalıdır(Cummings, 2004). Nitekim yukarıda bahsedildiği üzere, kuraklık nedeniyle insanların su depolamaya başlaması vektörler için yeni yaşam alanları oluşturacağından hastalık bu şeklide de artış gösterebilmektedir(WHO, 2003).

Dang ateşli hastalığı; mevsimsel olarak görülen ve genellikle sıcak ve nemle ilişkilendirilen bir hastalıktır. Kimi bölgelerdeki artan yağışlar bu hastalığı yayan vektörlerin sayısındaki artışı açıklayabilmektedir. Bu bağlamda hastalığın bulaşma imkânı bulabilmesi için El Nino'nun bazı bölgelerde kuraklıkların yaşanmasına ve su kaynaklarının azalmasına sebep olarak, dolaylı olarak etkisini göstermesi gerekebilmektedir(Mcdonald, 1957).

1970 ile 1995 yılları arasında Güney Pasifikte dang virüsünün bölgedeki yıllık ortalama değerleri ile La NINA; arasında pozitif bir ilişkinin olduğu anlaşılmıştır. Bu dönemlerde yaşanan La NiNA; Samoa, Nauru, Tokelau ve Wallis gibi ada ülkelerinde sıcaklık ve nemin normallerin üzerinde yaşanmasına sebep olmuştur. Artan sıcaklık ve nem değerleri, vektörlerin yaşaması ve çoğalması için uygun ortamı sağlamış ve hastalığın yayılmasındaki nedenlerden birisini oluşturmuş̧ur. Bu küçük adalarda beliren endemik hastalıklar, nüfus hareketleri sebebiyle komşu adalara ve daha yoğun nüfuslu bölgelere taşınmıştır. $\mathrm{Bu}$ da dang virüsünün bir bölgede görülmesini sadece iklimsel değişimlere yüklemenin doğru olmayacağını göstermektedir. Nitekim bölgesel ve çevresel faktörler de hastalığın yayılmasında etkili olabilmektedir(WHO, 2003).

Dang virüsü ile ilgili olarak Vietnam'da yapılan bir çalışmada; El Nino döneminde dang vakalarında artışların yaşandığı saptanmıştır(Glantz, 1996). Ancak coğrafi olarak benzer bir konumda olan Taylan'da El Nino ile dang virüsü arasında herhangi bir korelasyona rastlanamamıştır(Hay, 2000). Bu çalışmalarda dang virüsündeki artışla ilgili olarak çevresel ve risk faktörleri tanımlanmamıştır. Bölgesel ve küresel ölçekte yapılan çalışmalarda El Nino'nun dang faaliyetlerini etkileyip etkilemediğinin, eğer etkiliyorsa bunu hangi parametrin (sıcaklık, yağış, nem, deniz seviyesi yükselmesi veya rüzgar hızı gibi) etkilediğinin belirlenmesine ihtiyaç vardır(WHO, 2003).

\section{3.İshal}

İnsanlarda meydana gelen dahili hastalıkların çoğu iklimlere duyarlı olarak mevsimsel özellik göstermekte ve dönemsel olarak ortaya çıkmaktadır. Özellikle tropik bölgelerde görülen ishal vakaları yağışlı mevsimlerde zirve değerlere ulaşmaktadır. Ekstrem yağışların sebep olduğu seller, taşkınlar ile meydana gelen kuraklıkların her biri ishal vakalarıyla ilişkilendirilebilmektedir. Ekstrem yağışlar yeraltı sularına ve şehir içme suyu şebekelerine karışmak suretiyle içme sularını kirletebilmektedir. Şehir şebeke sularının kriptosporidyum, Kolera, Coli Basili, Tifo, ve Hepatit A gibi virüslerle kirletilmesiyle ishal vakaları meydana gelebilmektedir. Ayrıca, uzun süren kuraklıklar temiz su kaynaklarının miktarını azaltarak bu kaynaklara ulaşılabilirliği kısıtlamakta ve hastalığın yayılasını kolaylaştırabilmektedir. Nitekim zaman serileri analizi yöntemiyle yapılan bir çalışmada bulanık ve kirli suların mide hastalıklarına sebep olduğu ve Amerika'da sudan kaynaklanan rahatsızlıkların yaklaşık yarısının ekstrem yağışlar sonrası meydana geldiği belirlenmiştir(Curriero, 2001).

Diğer taraftan, sıcaklıkların yükselmesi enfeksiyona sebep olan mikropların gelişmesi için uygun ortamlar oluşturur. 1997 yılında meydana gelen El Nino'nun etkisiyle Peru'nun başkenti Lima'da mevsim normallerin üzerinde sıcaklıklar yaşanmıştır. Bu dönemdeki ishal ve vücudun aşırı su kaybetmesi nedeniyle meydana gelen rahatsızlıklar nedeniyle hastanelere başvuranların sayısında büyük artış gözlemlenmiştir(Salazar-Lindo, 1997). Günlük verilerden oluşturularak yapılan zaman serileri analizinde, Lima' da her 10Clik sıcaklık artışının hastaneye başvuranların sayısını \% 8 oranında arttırdığı ortaya çıkmıştır(Checkley, 2000).

Pasifik Adalarında 1978-1986 dönemlerinde yapılan bir analizde ise ishal vakaları ile ortalama sıcaklıklardaki artış arasında büyük bir paralelik görülmüş, aynı çalışmada suya ulaşılabilme imkânları ile ishal vakaları arasında da ters yönlü bir ilişki saptanmıştır(Singh, 2001). Fiji Adaları'nda 1978- 
1992 yılları arasındaki dönemi kapsayan zaman serileri analizine göre her 1 0C sıcaklık artışının bölgedeki ishal vakalarını \%3 oranında arttırdığı saptanmıştır. Bu analizde ayrıca ekstrem yağışlar ile ishal vakaları arasında anlamlı ilişkiler bulunmuştur(Singh, 2001).

\subsection{Kemirgen Kaynaklı Hastalıklar}

Kemirgen kaynaklı hastalıklar, çoğunlukla kemirgenlerin idrar, dışkı ve diğer atıklarıyla temasta bulunulmasıyla insanlara bulaşabilmektedir (Mills ve Childs, 1994). Ayrıca pire ve kene gibi eklembacaklıların kemirgen hayvanlar üzerlerinde barınma imkânı bulması da insan sağlığını tehdit edebilmektedir. Ani ve büyük miktardaki yağışlar ve kuraklık gibi iklimsel faktörler hastalık yayma potansiyelleri olan bu canlıların popülasyon dinamiklerini etkileyerek hastalık riskini yükseltmektedirler.

\subsubsection{Leptozpiroz}

Leptozpiroz, (leptospirosis) leptospira bakterisinin sebep olduğu akut ateşli bir hastalıktır. Tropik bölgeler başta olmak dünyanın çeşitli bölgelerinde görülen en yaygın hastalıklardan birisidir(PAHO, 1998). Leptozpiroz enfeksiyonu; suların, nemli toprakların veya sebze meyvelerin kemiricinin veya kedi/köpeklerin idrar, dışkı veya diğer atıklarıyla kirlenmesi suretiyle bu meyve ve sebzeleri tüketen insanlara geçmektedir(Thiermann, 1980). Dünyanın çeşitli bölgelerinde ve dönemsel veriler ışığında yapılan çalışmalarda, leptozpiroz vakalarının, ekstrem yağışlardan ve bunun sebep olduğu sellerden sonraki dönemlerde artış gösterdiği görülmüştür. Ekstrem yağışlar ve sellerdeki herhangi bir artış El NiNO ile ilişkilendirildiğinden leptozpiroz vakalarındaki artışın sebebini de dolaylı olarak El NINO vakalarında aramak mümkündür.

\subsubsection{Hantavirüs}

Hantavirüs "Sigmodon Hispidus" adı verilen ve anavatanı Güney, Orta ve Kuzey Amerika olan, pamuk faresi tarafından taşınan bir virüstür. Adını Güney Kore'deki Hantaan nehrinden almaktadır. $\mathrm{Bu}$ fare türü kırsal bölgelerde yaşamakla birlikte yaşam alanlarının daralması gibi çeşitli nedenlerle şehirlerde yaşayan insanlar için tehdit oluşturabilmektedir. Hantavirüs insanlara; insanların bu türün dışkısını solumaları veya bu tür tarafından isırılmalarıyla geçmektedir.

Kanamalı ve ateşli bir hastalık olan Hantavirüs; Çin, Kore ve Amerika'da görülmektedir. Hastalık vakalarındaki dalgalanmalar her yıl farklılık gösteren kemirgen popülasyonundaki değişmelere ve hava şartlarına bağlanabilmektedir(Glass vd., 2000) Hantavirüs enfeksiyonlarının çoğu sosyo-ekonomik bakımdan düşük düzeydeki, elverişli bir barınma imkânı bulunmayan ve tarımsal faaliyetleri sebebiyle kemirgenlerle sıkça temasta bulunan insanlarda görülmektedir(Schmaljohn, 1997).

1990'l1 yılların başlarında yapılan araştırmalarda, ABD'nin Güneyinde yaşanan hantavirüs vakaları ile kemirgen popülasyonundaki değişim arasında ilişki kurulmuştur(Wenzel, 1994). Şöyle ki; kuraklık sebebiyle azalan kemirgen popülasyonu, kuraklık döneminde bölgedeki böcek popülasyonunun artmasına olanak sağlamıştır. Bu da ilerleyen yıllarda av-avcı ilişkisi çerçevesinde bol miktarda besin bulabilen kemirgen popülasyonda 1992 yılından 1993 yılına kadar büyük bir artışa sebep olmuştur(Wenzel, 1994). Bir başka çalışmada ise, 1998 yılında ABD'de görülen hantavirüs vakaları, 1997/1998 yıllarındaki El Nino 'nun etkisiyle daha 1lık ve daha nemli geçen kış mevsiminin çevresel şartlarıyla açıklanmıştır(Hjelle ve Glass, 2000).

\subsubsection{Lyme}

Lyme hastalığı kene vasıyasıyla insanlara bulaşan yaygın bir hastalıktır. Yeni bulgular lyme vakalarındaki artışın sebebinin sıcaklık(Ogden vd., 2004) ve yağışlardaki(Mccabe ve Bunnell, 2004)artışlar oluşturduğunu söylemektedir. Sıcaklık ve buhar basıncı Lyme hastalığını yayan siyah bacaklı kene türünün (Ixodes scapularis) çoğalması için uygun ortamı hazırladığından, bu hastalık türü 
yayılma imkânı bulabilmektedir. Ayrıca, hastalığı yayan kenelerin yaşayabilmesi için aylık ortalama sıcaklık değerlerinin $-70 \mathrm{C}$ ve üzerinde gerçekleşmesi yeterli olmaktadır(Brownstein ve Holford, 2003). Önceleri deniz seviyesine yakın, 1lıman alçak rakımlı bölgelerde görülen bu hastalık, küresel ısınmanın etkisiyle ısınan yükssek enlemlerde de görülmeye başlamıştır.

\subsubsection{Veba}

Veba, kemirgenler üzerinde taşınan "Xenopsylla cheopis" denen pire türünün 1sırması ve içerdiği bulaşıcı bakterileri yayması yoluyla bulaşan bakteriyel bir hastalıktır. Nadiren de olsa virüs bulaşmış hayvanlarla direkt temasta bulunulmasıyla insanlara geçebilmektedir. Günümüzde veba, Avrupa kıtası hariç her bölgede görülebilmektedir. Geçen yıllarda bazı Asya, Afrika ve Güney Amerika ülkelerinde önemli veba olayları görülmüştür. El Nino'nun veba vakalarının yaşanmasına sebep olduğu konusunda herhangi bir netlik bulunmamasına rağmen kemirgen popülasyonun nemli ve çok yağışlı kışlarda artış göstermesi(Mills, 2003) yağışlarla kemirgen popülasyonu arasında kurulan ilişkiyi anlamlı hale getirmektedir.

New Mexico'da yapılan bir çalışmada, veba olaylarıyla ortalama yağış miktarının üzerinde gerçekleşen kış-ilkbahar dönemlerindeki yağışlardan sonra sık sik karşılaşıldığ 1 tespit edilmiştir(Parmenter, 1999). Bu yağışlar sebebiyle oluşan sslak ve nemli ortamlar, kemirgenlerin besin bulma imkânlarını artırarak, kemirgen üzerinde yaşayan pire ve kene gibi hastalık virüsü taşıyan canlıların barınma ve üreme şanslarını arttırabilmektedir.

\section{Sonuç}

Küresel 1sınma ve iklim değişikliğinin etkisini arttırarak hissettirdiği günümüzde, 2 ila 7 yıl arasında tekrarlanan El Nino olaylarının yaşanma periyotlarının daralması beklenmektedir. Sıkça yaşanmaya başlayacak olan bu ekstrem iklim olaylarının ise insan sağlığını doğrudan ve dolaylı olarak yoğun bir şekilde etkileyeceği açıktır. Hastalık riskinin yüksek olduğu ülkelerdeki, alt yap1 yetersizlikleri ve sosyo-ekonomik durumlarının istenilen düzeyde olmaması durumu daha da ağırlaştıracaktır.

Gelecek yıllarda küresel ısınma ve iklim değişikliğinin etkisiyle daha sık görülmeye başlayacak olan El Nino'lar; basit ve karmaşık ekstrem hava olaylarını tetikleyerek bulaşıcı hastalıkların daha geniş coğrafyalarda etkili olmasına yol açacaktır. Nitekim insan sağlığını tehdit eden vektör ve patojenler, El Nino dönemlerinde, ekstrem iklim olayları sonrası, çoğalıp yayılmaları için uygun nem ve 1sı değerleriyle karşılaştıklarından, bulaşıcı hastalık riskinin artmasına yol açacaklardır.

El Nino dönemlerinde meydana gelen ekstrem yağışlar, atık suların kullanım sularına bulaşmasını kolaylaştıracaktır. Kirlenen kullanım suları nedeniyle de Güney Asya ülkelerinde kolera ve ishal gibi hastalıkların sayısında artışlar yaşanacaktır. Diğer taraftan, Orta ve Batı Afrika ülkelerinde meydana gelecek ekstrem yağışlar ve/veya uzun süren kurakliklar sivrisinek, kene, pire ve diğer kemirgen türü vektörlerin yaşam alanlarının genişlemesine sebep olacaktır. Daha geniş alanlarda yaşama imkânı bulacak olan bu vektörler; bölgede sıtma, dang humması, veba, leptozpiroz, hantavirüs ve lyme gibi hastalıkları arttıracaktır. Gelişmiş batı toplumlarında ise, bu ülkelerdeki bölgeler arası gelişmişlik farkları nedeniyle yukarıda belirtilen hastalıkların yaşanması beklenmedik bir durum olmaktan çıkacaktır. 


\section{El Nino Döneminde Yaşanan Ekstrem Hava Olaylarının Bulaşıcı Hastalıklar Üzerindeki Etkileri}

\section{Kaynaklar}

Brownstein J.S. ve T.R. Holford, D. A. Fish (2003) "Climate-Based Model Predicts The Spatial Distribution Of Lyme Disease Vector Ixodes Scapularis İn The United States” Environ Health Perspective, Say1:111, s:7.

Bradley, D.J. (1993)"Human Tropical Diseases in a Changing Environment”, Environmental Change and Human Health. Ciba Foundation Symposium, s:175: 146-162

Brown, V., Epidemic of Malaria in North-Eastern Kenya, Lancet,Say1: 352, 1998, s: 1356-1357.

Chandler, J.A, and R.B., Highton (1975) "The Succession of Mosquitoes Species in Rice Fields Rice Fields in Western Kenya”, Bulletin Ofentomological Research, 65, 295-302

Curriero, F.(2001) "The Association Between Extreme Precipitation and Waterborne Disease Outbreaks in The United States, 1948-1994”, American Journal Of Public Health, Say1: 91(8), s:1194-1199.

Checkley, W. (2000)"Effects of El Niño and Ambient Temperature on Hospital Admissions for Diarrhoeal Diseases in Peruvian Children”. Lancet, Say1:355.

Cummings, D.A.(2004) “Travelling waves in the occurrence of dengue haemorrhagic fever in Thailand”, Nature, 427, s:344.

Diaz, H.F. ve P.D. Jones (2000) Climate and Human Health Linkages on Multiple Timescales: Climate And Climatic Impacts Through The Last 1000 Years, Cambridge, UK, Cambridge University Press.

Gagnon, A.(2002 )“The El Niño Southern Oscillation and Malaria Epidemics in South America”. International Journal of Biometeorology,Sayı:46, s:81-89.

Glass, G., J. Cheek, J.A. Patz, T.M. Shields, T.J. Doyle, D.A. Throughman, D.K. Hunt, R.E. Ensore, K.L. Gage, C. Ireland, C.J. Peters, and R. Bryan (2000) "Predicting High Risk Areas for Hantavirus Pulmonary Syndrome with Remotelysensed Data" The Four Corners Outbreak, Sayı: 6, s:238-247.

Garnham,P.C.C.(1945) "Malaria Epidemicsat Exceptionally High Altitudes İn Kenya”, British Medical Jurnal, ii, s:45-47.

Gill, C.A.(1920) “The Relationship of Malaria and Rainfall”, Indian Journal of Medical Research,7(3): s:618-632.

Glantz, M.H.(1996) Currents Of Change: El Niño's İmpact on Climate and Society, Cambridge, UK, Cambridge University Press (WHO, Climate Change and Human Health: Risk and Responses, 2003, s:84'deki alıntı)

Gubler, D.J.(1997) Dengue and dengue hemorrhagic fever: its history and resurgence as a global public health problem. In: Dengue And Dengue Hemorrhagic Fever, Gubler, D.J. \& Kuno, G. New York, USA, CAB International: 1-22.

Hamilton, A.C,(1989) The climate of the East Usambaras. İn: Forest Conservation in the East Usambaras, Switzerland, s: 99102

Hay, S.I.(2000) "Etiology Of İnterepidemic Periods of Mosquito-Borne Disease", Proceedings of the National Academy of Sciences, Say1: 97(16), s: 9335-9339

Hjelle, B. and G.E. Glass (2000) "Outbreak of hantavirus infection in the Four Corners region of the United States in the wake of the 1997-1998 El Niño-Southern Oscillation” Journal Of Infectious Diseases, Say1:181(5), s:1569-1573.

IPCC (2007) Human Health, Executive Summary, Working Group II: Impacts, Adaptation and vulnerability: Cambridge University Press, Cambridge ix, s:976.

IPCC(1996) Climate Change 2001: IPCC Third Assessment Report, Geneva, Switzerland, 2001.

Lindsay,S.W. ve M.H.Birley, “Climate Change And Malaria Transmission”, Annals Of Tropical Medicine And Parasitology, 90, s: 573-588.

Kovats R. (1999)El Niño and Health, Geneva, Switzerland, WHO.

Mills, J.N. ve Childs, J.E.(1998)Ecologic Studies Of Rodent Reservoirs: Their Relevance for Human Health, Emerging Infectious Diseases, Say1: 4, s: 529-537.

Mills, J.N.(1999) "Long-Term Studies of Hantavirus Reservoir Populations in the Southwestern United States: Rationale, Potential and Methods" Emerging Infectious Diseases, say1:5, s: 95-101.

Mccabe G.J ve J.E. Bunnell(2005) "Precipitation and the occurrence of Lyme disease in the northeastern United States", Vector Borne Zoonotic Diseases, Sayı: 4(2), s:143.

Mcdonald, G.(1957)The epidemiology and control of malaria, Oxford, UK, Oxford University Press 


\section{Mehmet Akalın}

Ogden N.H, L.R. Lindsay, G. Beauchamp (2004) "Investigation of relationships between temperature and developmental rates of tick Ixodes scapularis (Acari: Ixodidae) in the laboratory and field” J. Med. Entomol, Say1: 41(4), s:622-633.

PAHO (Pan American Health Organization)(1998),Health in the Americas, Vol:1, Washington, DC, USA, s:347.

Parmenter, R.R.(1997)“Incidence of Plague Associated with İncreased Winter-Spring Precipitation in New Mexico" American Journal of Tropical Medicine and Hygiene, Say1: 61, 1999, s: 814-821.

Schmaljohn, C. and B. Hjelle, "Hantaviruses: A Global Disease Problem” Emerging Infectious Diseases, Say1: 3, s: 95-104.

Salazar-Lindo, E.(1997) “El Niño and Diarrhoea and Dehydration in Lima, Peru” Lancet, Sayı:350, s:1597-1598

Singh, R.B.K.(2001a) "The İnfluence of Climate Variation and Change on Diarrhoeal Disease in the Pacific Islands. Environmental Health Perspectives, Say1: 109, s:155-159.

Singh, R.B.K. (2001b) “The İnfluence of Climate Variation And Change on Diarrhoeal Disease in The Pacific Islands", Environmental Health Perspectives,Say1: 109, 2001, s:155-159.

Thiermann, A.B.(1980)"Canine leptospirosis in Detroit” American Journal of Veterinary Research, Say1: 41, s:1659-1661.

Wenzel, R.P.(1994) “A New Hantavirus İnfection İn North America” New England Journal of Medicine,Say1: 330, s:10041005.

WHO (2003)Climate Change and Human Health: Risk and Responses, Editors: A.J. McMichael, D.H. CampbellLendrum,C.F. Corvalán, K.L. Ebi, A.K. Githeko,J.D. Scheraga,A. Woodward, Geneva, s:79.

WHO(1999),El Nino And Health, Protection of the Human Environment Task Force on Climate and Health, Geneva, 1999, s: V.

WHO(1998) “El Niño and its health impacts” Weekly Epidemiological Record 20, 1998, s:148-152.

WHO (2009) Malaria WHO Fact Sheet No.94, World Health Organization, Geneva, Switzerland. 